\section{Infrared Absorption Spectrum of Butatriene in the LiF Region}

\section{S. J. C Y V I N}

Institutt for teoretisk kjemi, Norges tekniske høgskole, Trondheim, Norway

The butatriene molecule is of considerable interest, as it is the smallest hydrocarbon molecule with three double bonds. Its structure in the gaseous state has been investigated by Raman high-resolution spectroscopy, ${ }^{1}$ and electron diffraction. ${ }^{2}$ Neither of these investigations contradict the assumption of a planar structure with linear carbon chain (symmetry: $D_{2 h}$ ) in the equilibrium position.
Some infrared bands of butatriene have been reported ${ }^{3}$ in connection with the synthesis of the compound, but no vibrational analysis has been attempted. Dr. Eggers ${ }^{4}$ kindly supplied to me a tentative assignment of some infrared bands, but still many uncertainties remain. We have taken up again this problem, trying to make an assignment of at least the infrared-active frequencies. ${ }^{5}$ Unfortunately there are great difficulties in taking a Raman spectrum in the liquid, due to rapid polymerization. ${ }^{4}$

In the present work the infrared absorption spectrum in the $\mathrm{LiF}$ region is reported. It has been recorded in 1958, using a sample prepared by Dr. Else KlosterJensen. ${ }^{2}$ The observed maxima are given in Table 1. The four most prominent bands (band centra: 1607, 1711, 3001, and $3059 \mathrm{~cm}^{-1}$ ) are reproduced in Figs. 1 and 2 .

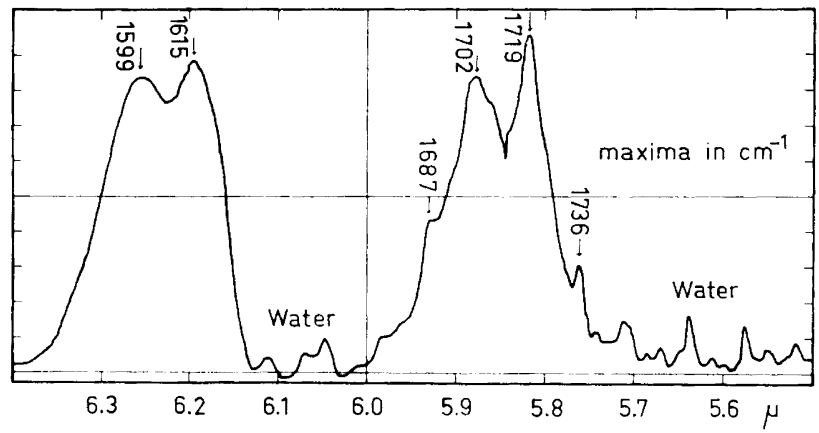

Fig. 1. I.R.-Spectrum of butatriene in the range 5.6 to $6.4 \mu$. Gas $10 \mathrm{~cm}$, equilibrium temperature $-19^{\circ} \mathrm{C}$, prism $\mathrm{LiF}$.

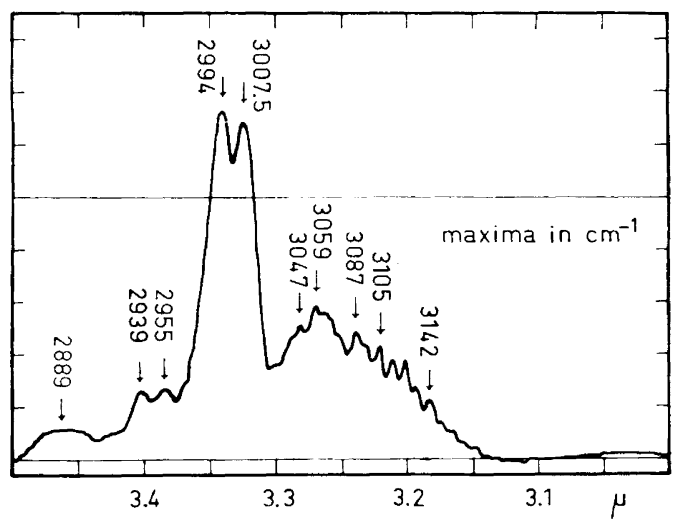

Fig. 2. I.R.-Spectrum of butatriene in the range 3.0 to $3.5 \mu$. Experimental conditions as in Fig. 1.

Acta Chem. Scand. 17 (1963) No. 7 
Table 1. Observed infrared LiF spectrum of butatriene: gas $10 \mathrm{~cm}$, equilibrium temperature $-19^{\circ} \mathrm{C}$.

\begin{tabular}{|c|c|c|}
\hline $\begin{array}{l}\text { Band centra } \\
\left(\mathrm{cm}^{-1}\right)\end{array}$ & $\underset{\left(\mathrm{cm}^{-1}\right)}{\operatorname{Maxima}}$ & Intensity \\
\hline \multirow{3}{*}{1607} & / 1599 & vs \\
\hline & $\{1615$ & vs \\
\hline & 1687 & $\mathbf{s}$ \\
\hline \multirow{4}{*}{1711} & / 1702 & vs \\
\hline & $\{1719$ & vs \\
\hline & 1736 & $\mathbf{s}$ \\
\hline & 1969 & $w$ \\
\hline \multirow{6}{*}{2034} & f 2026 & $\mathbf{s}$ \\
\hline & $\{2041$ & $\mathbf{s}$ \\
\hline & 2475 & $w$ \\
\hline & 2889 & $w$ \\
\hline & 2939 & w \\
\hline & 2955 & $w$ \\
\hline \multirow{9}{*}{3001} & / 2994 & vs \\
\hline & 3007.5 & vs \\
\hline & $(3030)$ & fine \\
\hline & \begin{tabular}{|l|}
$\mathbf{3 0 4 0}$ \\
$\mathbf{3 0 4 7}$
\end{tabular} & structure \\
\hline & 3059 & $\mathrm{~s}$ \\
\hline & 3066 & \\
\hline & 3076 & \\
\hline & 3087 & \\
\hline & 3095 & \\
\hline \multirow{14}{*}{3059} & 3105 & \\
\hline & 3115 & \\
\hline & 3123 & fine \\
\hline & 3132 & structure \\
\hline & 3142 & \\
\hline & 3152 & \\
\hline & 3160 & \\
\hline & 3170 & \\
\hline & 3178 & \\
\hline & 3448 & $\mathbf{w}$ \\
\hline & 4082 & $w$ \\
\hline & 4141 & w \\
\hline & 4484 & $\mathbf{w}$ \\
\hline & 4651 & $w$ \\
\hline
\end{tabular}

1. Stoicheff, B. P. Can. J. Phys. 35 (1957) 837.

2. Almenningen, A., Bastiansen, $O$. and Trætteberg, M. Acta Chem. Scand. 15 (1961) 1557.

3. Schubert, W. M., Liddicoet, T. H. and Lanka, W. A. J. Am. Chem. Soc. 76 (1954) 1929.

4. Eggers, Jr., D. F. Private communication (1958).

5. Klæboe, P. and Cyvin, S. J. To be published.

Received July 22, 1963.

\section{Effect of Irradiation Temperature on the Yield of Solute Radicals in Frozen Aqueous Solutions}

\author{
A. P I H L, T. SA N N E R * and \\ T. H E N I K S E N *
}

Norsk Hydro's Institute for Cancer Research, Montebello, Norway

In the present communication data are reported on the effect of the irradiation temperature on the efficiency of the indirect action of ionizing radiation.

When solutions are exposed to ionizing radiation, free radicals are induced in the solvent as well as in the solute. At $77^{\circ} \mathrm{K}$ or lower, there is little or no interaction between solvent radicals and solute molecules. Under these conditions the solute radicals, as revealed by electron spin resonance (ESR) spectroscopy, are formed predominantly by direct action. ${ }^{1-3}$ When frozen aqueous solutions are heat-treated after irradiation, the radicals induced in the water disappear in the temperature range $100^{\circ}$ to $130^{\circ} \mathrm{K}$, largely by recombination reactions. Some of the radicals will, however, interact with the solute molecules with the result that radiation energy is transferred to the solute. The extent of this indirect effect in frozen aqueous solutions irradiated at $77^{\circ} \mathrm{K}$ is small compared to that observed after irradiation in the liquid state..$^{3,4}$ Although the state of the solution is the most important factor in this respect, ${ }^{5,6}$ the possibility exists that the irradiation temperature as such may have a significant influence on the interaction of water radicals with solute molecules.

Frozen aqueous solutions of $\mathrm{DL}_{-}-\alpha$-alanine were irradiated in vacuum with $\mathrm{X}$-rays at different temperatures in the range $77^{\circ}$ to $195^{\circ} \mathrm{K}$. During the exposure (104 min) secondary reactions will occur in the solvent as well as in the solute. In order to eliminate possible differences in the extent of the secondary reactions at the different temperatures used, all samples were heat-treated for $3 \mathrm{~min}$ after the exposure. A temperature was chosen $\left(250^{\circ} \mathrm{K}\right)$ that was appreciably higher than the highest irradiation temperature. The ESR spectra were recorded at $77^{\circ} \mathrm{K}$. The

* Fellow of the Norwegian Cancer Society. 